\title{
JENIS TANAMAN, KERAPATAN, DAN STRATIFIKASI TAJUK PADA HUTAN KEMASYARAKATAN KELOMPOK TANI RUKUN MAKMUR 1 DI REGISTER 30 GUNUNG TANGGAMUS, LAMPUNG
}

\section{SPECIES, DENSITY, AND CANOPY STRATIFICATION OF SOCIAL FORESTRY OF THE FARMERS GROUP RUKUN MAKMUR 1 IN REGISTER 30 MOUNT TANGGAMUS LAMPUNG}

\author{
Oleh : \\ Wawan Septiawan, Indriyanto, dan Duryat \\ Jurusan Kehutanan, Fakultas Pertanian, Universitas Lampung \\ Jl. Soemantri Brojonegoro No.1 Bandar Lampung, 35145 \\ E-mail : wawanesylvaten@gmail.com
}

\begin{abstract}
ABSTRAK
Hutan lindung mempunyai fungsi pokok sebagai pelindung sistem penyangga kehidupan, mengatur tata air, mencegah banjir, mengendalikan erosi, mencegah intrusi air laut, dan memelihara kesuburan tanah. Kegiatan pemanfaatan hutan lindung sudah sejak lama dilakukan masyarakat sekitar hutan. Hutan kemasyarakatan merupakan kegiatan pemberdayaan masyarakat agar dapat mengelola hutan lindung secara lestari. Penelitian ini bertujuan untuk; 1) mengetahui jenis tanaman penyusun vegetasi hutan berdasarkan atas golongan tanaman kehutanan dan tanaman pertanian; 2) mengetahui kerapatan tiap golongan tanaman; dan 3) mengetahui stratifikasi tajuk hutan. Untuk mengetahui kondisi vegetasi hutan di areal garapan Kelompok Tani Rukun Makmur 1, dilakukan penelitian survai vegetasi dengan metode garis berpetak agar diperoleh gambaran tentang vegetasi hutan yang terbentuk melalui penerapan sistem HKm. Pengamatan dilakukan dengan pembuatan petak contoh sebanyak 31 buah. Pada penelitian ini ditemukan 36 jenis tanaman yang terdiri atas golongan kayu rimba 14 jenis, MPTs rimba 10 jenis, MPTs pertanian 9 jenis, tanaman pertanian tahunan 3 jenis, dan tidak ada tanaman pertanian semusim. Kerapatan tanaman untuk tiap golongan tanaman yaitu golongan kayu rimba 412,44 individu/ha, MPTs rimba 44,28 individu/ha, MPTs pertanian 25,40 individu/ha, dan pertanian tahunan 1.729,03 individu/ha. Stratifikasi tajuk yang terbentuk terdiri atas lima strata yaitu strata A, B, C, D, dan E.
\end{abstract}

Kata kunci: hutan kemasyarakatan, jenis tanaman, kerapatan, stratifikasi tajuk

\begin{abstract}
Protection forests have a protective function as a basic life support system to regulate the water system, prevent floods, control erosion, prevent sea water intrusion and maintaining soil fertility. This research aims to; 1) determined the type of forest vegetation component plants based on groups of forestry and agricultural crops; 2) determined the density of each type of plant; and 3) knowing the stratification of the forest canopy. To determined the condition of the forest vegetation in the area of arable land of farmer groups Rukun Makmur 1, the researcher conducted a vegetation survey with terraced line method in order to obtain an overview of the forest vegetation is formed through the implementation of community forestry system. Observations were made with the creation of as many as 31
\end{abstract}


pieces of sample plots. This study found 36 species of plants consisting of jungle wood class 14 types, 10 types of jungle MPTS, MPTS agriculture 9 types, 3 types of annual agricultural crops, and there is no seasonal agricultural crops. Plant density for each class of plants namely class jungle wood 412.44 individuals / ha, MPTS jungle 44.28 individuals / ha, agricultural MPTS 25.40 individuals / ha, and the annual agricultural 1729.03 individuals / ha. Stratification canopy is formed consisting of five strata are strata $A, B, C, D$, and $E$.

Key word: community forest, plant destiny, stratification canopy, type of plant

\section{PENDAHULUAN}

\section{Latar Belakang}

Hutan lindung ialah kawasan hutan yang mempunyai fungsi pokok sebagai pelindung sistem penyangga kehidupan untuk mengatur tata air, mencegah banjir, mengendalikan erosi, mencegah intrusi air laut, dan memelihara kesuburan tanah (Undang Undang Republik Indonesia Nomor 41 Tahun 1999 tentang kehutanan).

Hutan Kemasyarakatan $(\mathrm{HKm})$ adalah hutan negara yang pemanfaatan utamanya ditujukan untuk memberdayakan masyarakat setempat (Permenhut P. 88/Menhut-II/2014). Kawasan hutan yang dapat ditetapkan sebagai areal kerja hutan kemasyarakatan adalah kawasan hutan lindung dan kawasan hutan produksi yang tidak dibebani hak atau izin. Izin Usaha Pemanfaatan Hutan Kemasyarakatan (IUPHKm) dikeluarkan oleh Bupati atau Gubernur untuk lintas kabupaten. IUPHKm merupakan izin usaha yang diberikan untuk memanfaatkan sumber daya hutan pada kawasan hutan lindung dan atau kawasan hutan produksi. IUPHKm diberikan untuk jangka waktu 35 (tiga puluh lima) tahun dan dapat diperpanjang sesuai dengan hasil evaluasi setiap 5 (lima) tahun (Permenhut P. 88/MenhutII/2014).

Penggarapan lahan hutan lindung yang dilakukan oleh masyarakat pemegang izin kelola sering kali menyebabkan menurunnya fungsi hutan. Ini disebabkan karena berkurangnya tutupan tajuk yang menaungi permukaan tanah, sehingga stratifikasi tajuk yang selama ini terbentuk semakin lama semakin berkurang. Masyarakat lebih memilih tanaman pertanian semusim yang menghasilkan keuntungan lebih cepat.

Dipilihnya Kelompok Tani Rukun Makmur 1 sebagai lokasi penelitian karena izin pengelolaan hutan kemasyarakatan tergolong sudah lama. Terbentuk dan langsung tergabung dalam Koperasi Patria Panca Marga pada tahun 1999 yang berbadan hukum Nomor 132/BH/KDK.7.I/V/1999 tanggal 24 Mei 1999. Kemudian pada Tahun 2000 mendapatkan izin awal pemanfaatan Hutan Kemasyarakatan yang dikeluarkan oleh Kepala Kantor Wilayah Departemen Kehutanan Provinsi Lampung Nomor 313/Kwl-4/Kpts/2000 tanggal 25 Agustus 2000 selama tiga tahun. Pada tahun 2007 mendapat SK Penetapan areal dari Menteri Kehutanan dan IUPHKm dari Bupati Tanggamus (Unit Pelaksana Teknis Batu Tegi, 2007). Mengingat penerapan pemanfaatan lahan oleh kelompok tani Rukun Makmur 1 sudah cukup lama, yaitu 15 tahun, oleh karena itu perlu adanya studi terhadap vegetasi hutan yang dibangun oleh masyarakat melalui sistem $\mathrm{HKm}$ agar diperoleh gambaran tentang wilayah hutan yang terbentuk melalui penerapan sistem HKm ini.

Penelitian ini dilakukan dengan menggunakan metode jalur berpetak. Banyaknya petak contoh yang akan digunakan dalam penelitian ini adalah 31 petak dengan intensitas sampling yaitu sebesar $2 \%$ dari total keseluruhan daerah garapan Kelompok Tani Rukun Makmur 1. 


\section{Tujuan Penelitian}

1. Mengetahui jenis tanaman penyusun vegetasi hutan, kerapatan setiap jenis, dan rata-rata jarak antar tanaman.

2. Mengetahui jenis tanaman berdasarkan atas golongan tanaman kehutanan dan tanaman pertanian, serta perbandingan kerapatan tiap golongan tanaman.

3. Mengetahui jenis tanaman berdasarkan atas golongan kayu rimba, MPTS rimba, MPTS pertanian, dan tanaman semusim, serta perbandingan kerapatan tiap golongan tanaman.

4. Mengetahui stratifikasi tajuk dan jenis-jenis tanaman penyusun setiap strata tajuk hutan.

\section{METODE PENELITIAN}

\section{Waktu dan Lokasi Penelitian}

Penelitian berlokasi di kawasan hutan kemasyarakatan areal garapan Kelompok Tani Rukun Makmur I. Penelitian dilaksanakan selama 1 bulan, dimulai pada Bulan Juli 2015 Agustus 2015.

\section{Alat dan Bahan}

Objek penelitian adalah vegetasi yang terdapat di areal pengelolaan hutan kemasyarakatan. Alat-alat yang digunakan pada penelitian ini terdiri global positioning system (GPS) Garmin 72, roll meter kain ukuran $100 \mathrm{~m}$, pita ukur dengan ketelitian 0,01 mm, christen hypsometer, tali raffia ukuran $1 \mathrm{~kg}$, peta lokasi penelitian, dan kamera DSLR Nikon D3200 dengan ukuran 24.0 megapixel dan menggunakan lensa AF-S Nikkor 18--55 mm.

\section{Definisi Oprasional}

Untuk mempelajari kondisi vegetasi hutan di areal hutan kemasyarakatan diperlukan definisi dan batasan operasional, sebagai berikut.

1. Tanaman kehutanan adalah tanaman yang menghasilkan komoditi kehutanan, berupa kayu dan/atau nir kayu.

2. Tanaman pertanian adalah tanaman yang menghasilkan komoditi pertanian

3. Kayu rimba adalah jenis tanaman berkayu yang asalnya dari hutan dan hasil utamanya berupa kayu.

4. MPTs rimba adalah tanaman berkayu berhabitus pohon dan memiliki fungsi / manfaat ekonomis berupa komoditi kehutanan (kayu dan nir kayu), serta memiliki fungsi / manfaat ekologis.

5. MPTs pertanian adalah tanaman berkayu berhabitus pohon dan memiliki fungsi / manfaat ekonomis berupa komoditi pertanian (kayu dan nir kayu), serta memiliki fungsi / manfaat ekologis.

6. Tanaman pertanian tahunan adalah tanaman pertanian yang memiliki daur hidup panjang / tahunan.

7. Tanaman pertanian semusim adalah tanaman pertanian yang memiliki daur hidup pendek / semusim.

\section{Jenis Data}

Jenis data yang dikumpulkan berupa data primer meliputi komposisi spesies tumbuhan, tinggi pohon, diameter batang, dan penutupan tajuk. 


\section{Metode Pengumpulan Data}

1. Desain petak contoh

a. Metode yang digunakan pada penelitian ini adalah metode garis berpetak. Jumlah plot yang digunakan sebanyak 31 buah dengan jarak antar plot dalam satu garis rintis 100 meter, sedangkan jarak antar garis rintis sebesar 170 meter.

b. Intensitas sampling (IS) yang digunakan sebesar 2\%, luas lokasi 61,58 ha, sehingga jumlah plot sampel yang digunakan ditentukan sebagai berikut.

IS $=\frac{\text { luas seluruh plot sampel }}{\text { luas lokasi }} \times 100 \%$

Luas seluruh plot sampel $=$ IS $\times$ Luas Lokasi

$$
\begin{aligned}
& =2 \% \times 61,58 \mathrm{ha} \\
& =0,02 \times 615.800 \mathrm{~m}^{2} \\
& =12.316 \mathrm{~m}^{2}
\end{aligned}
$$

Jumlah plot sampel $=\frac{\text { luas seluruh plot sampel }}{\text { luas satu plot sampel }}$

$$
\begin{aligned}
& =\frac{12.316 \mathrm{~m}^{2}}{400 \mathrm{~m}^{2}} \\
& =30,79 \\
& =31 \text { buah }
\end{aligned}
$$

c. Pengambilan sampel menggunakan metode garis berpetak. Pada masing-masing petak $20 \mathrm{~m} \times 20 \mathrm{~m}$, dibuat petak pengamatan berukuran $10 \mathrm{~m} \times 10 \mathrm{~m}$ (pengamatan tingkat poles), $5 \mathrm{~m} \times 5 \mathrm{~m}$ (pengamatan tingkat sapling), dan $2 \mathrm{~m} \times 2 \mathrm{~m}$ (pengamatan tingkat seedling). Berikut adalah bentuk dari petak contoh dengan metode garis berpetak.

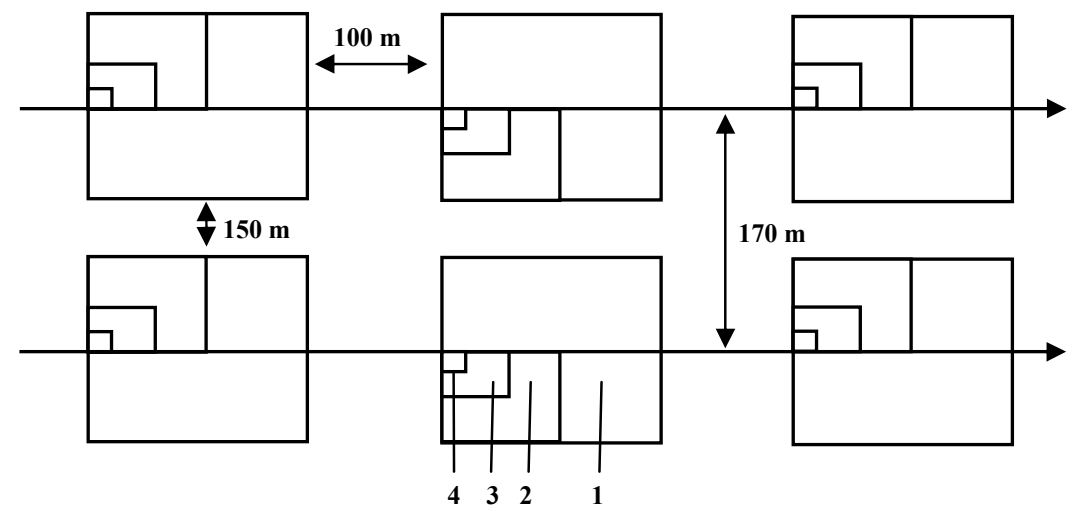

Gambar 1. Desain petak contoh menggunakan metode garis berpetak yang digunakan dalam penelitian.

Keterangan: 1 = petak ukur $20 \mathrm{~m}$ x $20 \mathrm{~m}$, untuk pengamatan tingkat pohon (pohon dengan diameter batang $\geq 20 \mathrm{~cm}$ )

2 = petak ukur $10 \mathrm{~m} \times 10 \mathrm{~m}$, untuk pengamatan tingkat tiang (pohon dengan diameter batang $10-19 \mathrm{~cm}$ )

3 = petak ukur $5 \mathrm{~m} \times 5 \mathrm{~m}$, untuk pengamatan tingkat sapihan (pohon dengan diameter batang $<10 \mathrm{~cm}$ )

4 = petak ukur $2 \mathrm{~m} \times 2 \mathrm{~m}$, untuk pengamatan tingkat semai (anakan pohon dengan tinggi $\leq 1,5 \mathrm{~m}$ ) 


\section{Analisis Data}

Analisis data yang digunakan pada penelitian ini berupa kerapatan setiap jenis tanaman, rata-rata jarak antar tanaman, dan penentuan stratifikasi tajuk. Kerapatan jenis digunakan bertujuan mengetahui tingkat kerapatan tiap golongan jenis tanaman dalam suatu areal pengelolaan per satuan unit areal pengelolaan, maka dilakukan perhitungan kerapatan dan rata-rata jarak anatar tanaman, dengan menggunakan rumus dibawah ini.

Kerapatan $(\mathrm{K})=\frac{\sum \text { pohon ditemukan didalam petak contoh }}{\text { luas petak contoh }}$

Rata-rata jarak antartanaman $=\sqrt{\frac{1}{\mathrm{~K}}}$

\section{Penentuan Stratifikasi Tajuk}

Stratifikasi tajuk ditentukan dengan menggunakan kriteria sebagai berikut.

a. Stratum A merupakan lapisan teratas yang terdiri dari pohon-pohon yang tinggi totalnya lebih dari $30 \mathrm{~m}$.

b. Stratum B terdiri dari pohon-pohon yang tingginya $20--30 \mathrm{~m}$.

c. Stratum $\mathrm{C}$ terdiri dari pohon-pohon dengan tinggi 4--20 $\mathrm{m}$

d. Statum D terdiri dari tumbuhan dengan tinggi $1--4 \mathrm{~m}$.

e. Stratum E, yaitu tajuk paling bawah (lapisan kelima dari atas) yang dibentuk oleh spesiesspesies tumbuhan penutup tanah (ground cover) yang tingginnya kurang dari 1 meter.

\section{HASIL DAN PEMBAHASAN}

\section{Jenis Tanaman}

Hasil penelitian menunjukkan bahwa tegakan di areal Hutan Kemasyarakatan Kelompok Tani Rukun Makmur 1 di register 30 Gunung Tanggamus tersusun atas 36 spesies. Spesies-spesies penyusun vegetasi tersebut tergolong pohon, perdu, dan liana. Berdasarkan Tabel 1, diketahui bahwa spesies tumbuhan sebagian besar $(80,55 \%)$ termasuk ke dalam habitus pohon, dan sebagian kecil $(19,44 \%)$ masuk ke dalam habitus herba, perdu dan liana. Tingginya jumlah jenis habitus pohon dibanding habitus perdu dan liana berkaitan dengan status kawasan yang merupakan kawasan hutan sehingga masyarakat harus menanam berbagai jenis pepohonan. Secara lengkap spesies penyusun vegetasi Hutan Kemasyarakatan Kelompok Tani Rukun Mankmur 1 di register 30 Gunung Tanggamus disajikan pada Tabel 1 berikut.

Tabel 1. Komposisi jenis tanaman penyusun vegetasi Hutan Kemasyarakatan Kelompok Tani Rukun Makmur 1 di register 30 Gunung Tanggamus

\begin{tabular}{cllll}
\hline No. & Nama Jenis Tanaman & Habitus & $\begin{array}{c}\text { Golongan } \\
\text { Tanaman }\end{array}$ & $\begin{array}{c}\text { Manfaat Ekonomi Bagi pemegang } \\
\text { IUPHKm }\end{array}$ \\
\hline 1 & Aleurites moluccana & Pohon & MPTS rimba & Biji sebagai rempah \\
\hline 2 & Alstonia scholaris & Pohon & Kayu rimba & - \\
\hline 3 & Arenga piñata & Pohon & MPTS rimba & Menghasilkan buah, nira, ijuk, sagu \\
\hline 4 & Arthocarpus heterophyllus & Pohon & MPTS pertanian & Menghasilkan buah \\
\hline 5 & Artocarpus communis & Pohon & MPTS rimba & Menghasilkan buah \\
\hline 6 & Artocarpus elasticus & Pohon & Kayu rima & - \\
\hline 7 & Bauhinia purpurea & Perdu & Kayu rimba & - \\
\hline 8 & Calliandra calothyrus & Perdu & Kayu rimba & Daun untuk pakan ternak, kayu bakar \\
\hline
\end{tabular}




\begin{tabular}{|c|c|c|c|c|}
\hline 9 & Calliandra tetragona & Perdu & Kayu rimba & Daun untuk pakan ternak, kayu bakar \\
\hline 10 & Canarium vulgare & Pohon & MPTS rimba & - \\
\hline 11 & Ceiba pentandra & Pohon & MPTS rimba & $\begin{array}{l}\text { Menghasilkan kapuk, daun untuk } \\
\text { pakan ternak }\end{array}$ \\
\hline 12 & Citrus maxima & Pohon & MPTS pertanian & Menghasilkan buah \\
\hline 13 & Coffea robusta & Perdu & Pertanian tahunan & Menghasilkan biji \\
\hline 14 & Dalbergia latifolia & Pohon & Kayu rimba & - \\
\hline 15 & Durio zibethinus & Pohon & MPTS rimba & Menghasilkan buah \\
\hline 16 & Eugenia aquea & Pohon & MPTS pertanian & Menghasilkan buah \\
\hline 17 & Eugenia aromatica & Pohon & MPTS pertanian & Menghasilkan bunga \\
\hline 18 & Eugenia malaccensis & Pohon & MPTS pertanian & Menghasilkan buah \\
\hline 19 & Eugenia polyantha & Pohon & MPTS rimba & Dimanfaatkan daunnya \\
\hline 20 & Ficus fulva & Pohon & Kayu rimba & - \\
\hline 21 & Ficus gibbosa & Pohon & Kayu rimba & - \\
\hline 22 & Gliricidia sepium & Perdu & Kayu rimba & daun untuk pakan ternak \\
\hline 23 & Gmelina arborea & Pohon & Kayu rimba & - \\
\hline 24 & Gnetum gnemon & Pohon & MPTS rimba & Menghasilkan buah, biji \\
\hline 25 & Mangifera odorata & Pohon & MPTS pertanian & Menghasilkan buah \\
\hline 26 & Meisopsis eminii & Pohon & Kayu rimba & - \\
\hline 27 & Michelia campaca & Pohon & Kayu rimba & - \\
\hline 28 & Musa paradisiaca & $\begin{array}{l}\text { herba } \\
\text { tahunan }\end{array}$ & Pertanian tahunan & Menghasilkan buah \\
\hline 29 & Mystica fragrans & Pohon & MPTS rimba & Menghasilkan buah dan biji \\
\hline 30 & Parkia speciosa & Pohon & MPTS rimba & Menghasilkan biji \\
\hline 31 & Persea americana & Pohon & MPTS pertanian & Menghasilkan buah \\
\hline 32 & Piper nigrum & Liana & Pertanian tahunan & Biji sebagai rempah \\
\hline 33 & Psidium guajava & Pohon & MPTS pertanian & Menghasilkan buah \\
\hline 34 & Swietenia macrophlla & Pohon & Kayu rimba & - \\
\hline 35 & Theobroma cacao & Pohon & MPTS pertanian & Menghasilkan buah \\
\hline 36 & Toona sureni & Pohon & Kayu rimba & - \\
\hline
\end{tabular}

Skema HKm yang diterapkan pada lahan hutan lindung mengharuskan masyarakat untuk tetap menanam jenis kayu-kayuan guna menjaga fungsi pokok dari hutan lindung tersebut. Dari hasil survai vegetasi yang telah dilakukan ditemukan jenis tanaman yang tergolong kayu rimba 14 jenis, MPTs rimba 10 jenis, MPTs pertanian 9 jenis, pertanian tahunan 3 jenis, dan tidak ditemukan satupun jenis tanaman pertanian semusim. Jenis tanaman kekayuan yang ditemukan merupakan hasil penanaman masyarakat secara mandiri sebelum mendapatkan IUPHKm.

Tujuan ditanamnya jenis kekayuan tersebut awalnya akan dimanfaatkan kayunya untuk dijual, namun setelah didapatkannya izin $\mathrm{HKm}$, masyarakat tidak berani menebang pohon karena adanya larangan menebang pohon di areal garapan. Larangan ini tertulis pada Permenhut P.88/Menhut-II/2014 yang menyatakan masyarakat pemegang IUPHKm hanya dapat memanfaatkan hasil hutan bukan kayu saja. Tumbuhan penyusun vegetasi HKm kelompok tani Rukun Makmur 1 sebagian besar merupakan jenis tanaman yang memiliki manfaat ekonomi, baik itu dari hasil buah maupun kayunya.

Berdasarkan peraturan tersebut, masyarakat dilarang melakukan penebangan kayu. Oleh karena itu masyarakat yang memiliki hak kelola lahan cenderung menanam jenis tanaman yang memiliki manfaat ekonomi selain kayu dan akan membuang jenis tanaman yang tidak memiliki hasil hutan bukan kayu. Akibatnya keragaman spesies tumbuhan yang ditemukan relatif rendah jika dibandingkan dengan hutan alam. Yusuf dkk. (2005) melaporkan di hutan lindung Rimbo Panti Sumatera Barat ditemukan lebih dari 200 spesies. Hal ini menunjukkan hutan lindung Register 30 Gunung Tanggamus yang memiliki kondisi 
dan spesies tumbuhan yang relatif sama dengan Hutan Lindung Panti rimbo dari segi biodiversiti telah banyak berkurang karena pengolahan lahan oleh masyarakat.

\section{Kerapatan Berdasarkan Golongan Jenis Tanaman Tiap Fase Pertumbuhan}

Berdasarkan analisis yang telah dilakukan diketahui bahwa beberapa jenis pohon yang masuk kedalam golongan kayu rimba regenerasinya berjalan tidak baik. Hal ini ditandai dengan tidak ditemukannya salah satu atau lebih fase pertumbuhan. Namun, untuk jenis perdu regenerasi berjalan dengan baik dilihat dari banyaknya fase semai yang menandakan regenerasi sedang berjalan.

Keberadaan anakan spesies pohon dalam hutan akan mencerminkan kemampuan hutan untuk beregenerasi. Tingginya kerapatan tumbuhan perdu dipegaruhi oleh ketertarikan masyarakat dalam membudidayakan tumbuhan tersebut. Masyarakat cenderung menanam jenis yang memiliki manfaat langsung seperti jenis perdu yang ditanam merupakan jenis Leguminosae. Jenis tanaman ini dikenal dapat menyuburkan tanah, dapat menjadi peneduh bagi tanaman pokok yaitu kopi robusta, serta dimanfaatkan sebagai pakan ternak (Rukmana, 2014). Jenis-jenis tersebut lebih disukai dibandingkan kekayuan yang tidak memberi kontribusi ekonomi bagi masyarakat. Karena semua pohon yang tumbuh di areal HKm tidak boleh ditebang sehingga masyarakat enggan menanam jenis kekayuan yang tidak memberikan hasil hutan selain kayu.

Selain dapat digunakan sebagai pupuk hijau, jenis tanaman Leguminosae juga dapat dijadikan tanaman penutup tanah. Menurut Arsyad (2006) tanaman penutup tanah adalah tumbuhan atau tanaman yang khusus ditanam untuk melindungi tanah dari ancaman kerusakan oleh erosi dan/atau untuk memperbaiki sifat kimia dan fisik tanah. Peran tanaman penutup tanah dapat mengurangi kekuatan disperse air hujan, mengurangi jumlah serta kecepatan aliran permukaan dan memperbesar infiltrasi air kedalam tanah, hingga mengurangi erosi. Jenis tanaman dengan habitus perdu seperti Calliandra calothyrsus dan Gliricidia sepium akan efektif menahan erosi jika digunakan sebagai tanaman pagar (Arsyad, 2006). Beberapa jenis Leguminosae yang banyak ditemukan di lokasi penelitian berhabitus perdu yang ditanam diantara baris tanaman kopi, pisang, dan juga digunakan sebagai media tumbuh tanaman lada. Kerapatan setiap kelompok tanaman yang ditemukan di HKm kelompok tani Rukun Makmur 1 disajikan pada Tabel 2 berikut ini.

Tabel 2. Kerapatan tiap jenis tanaman yang ditemukan di HKm kelompok tani Rukun Makmur 1

\begin{tabular}{|c|c|c|c|c|c|c|}
\hline \multirow[b]{2}{*}{ No } & \multirow[b]{2}{*}{ Jenis Tanaman } & \multicolumn{4}{|c|}{ Kerapatan (individu/ha) } & \multirow{2}{*}{$\begin{array}{c}\text { Total } \\
\text { (individu/ha) }\end{array}$} \\
\hline & & $\begin{array}{c}\text { Fase } \\
\text { Semai }\end{array}$ & $\begin{array}{c}\text { Fase } \\
\text { Sapihan } \\
\end{array}$ & $\begin{array}{c}\text { Fase } \\
\text { Tiang } \\
\end{array}$ & $\begin{array}{c}\text { Fase } \\
\text { Pohon }\end{array}$ & \\
\hline 1 & Persea americana*** & 0 & 0 & 9,68 & 8,87 & 18,55 \\
\hline 2 & Arenga pinata $* *$ & 0 & 0 & 0 & 3,23 & 3,23 \\
\hline 3 & Ficus fulva* & 0 & 0 & 0 & 3,23 & 3,23 \\
\hline 4 & Artocarpus elasticus* & 0 & 0 & 0 & 4,84 & 4,84 \\
\hline 5 & Michelia campaca* & 0 & 0 & 0 & 0,81 & 0,81 \\
\hline 6 & Eugenia aromaticum $* * *$ & 0 & 12,9 & 0 & 0 & 12,90 \\
\hline 7 & Durio zibethinus $* *$ & 322,58 & 0 & 3.23 & 8,87 & 334,68 \\
\hline 8 & Glicidia speum* & 241,94 & 451,61 & 183.87 & 15,32 & 892,74 \\
\hline 9 & Eugenia aquea $* * *$ & 0 & 0 & 3.23 & 0 & 3,23 \\
\hline 10 & Psidium guajava*** & 161,29 & 0 & 3.23 & 0 & 164,52 \\
\hline 11 & Eugenia malaccensis $* * *$ & 0 & 0 & 0 & 0,81 & 0,81 \\
\hline 12 & Citrus maxima*** & 0 & 0 & 0 & 0,81 & 0,81 \\
\hline 13 & Theobroma cacao*** & 0 & 12,9 & 6.45 & 0 & 19,35 \\
\hline 14 & Calliandra calothrsus* & $2.983,87$ & 232,26 & 35.48 & 0 & $3.251,61$ \\
\hline
\end{tabular}




\begin{tabular}{|c|c|c|c|c|c|c|}
\hline 15 & Calliandra tetragona* & $1.451,61$ & 25,81 & 0 & 0 & $1.477,42$ \\
\hline 16 & Meiopsis eminii* & 0 & 0 & 0 & 1,61 & 1,61 \\
\hline 17 & Ficus gibbosa* & 0 & 0 & 0 & 0,81 & 0,81 \\
\hline 18 & Aleurites moluccana** & 0 & 0 & 0 & 12,90 & 12,90 \\
\hline 19 & Canarium vulgare** & 0 & 0 & 0 & 3,23 & 3,23 \\
\hline 20 & Kopi robusta $* * * *$ & $1.532,26$ & $2.245,16$ & 638.71 & 0 & $4.416,13$ \\
\hline 21 & Кири-kири* & 0 & 0 & 6.45 & 0 & 6,45 \\
\hline 22 & Piper nigrum $* * * *$ & 322,58 & 0 & 0 & 0 & 322,58 \\
\hline 23 & Swietenia macrophlla* & 0 & 0 & 0 & 6,45 & 6,45 \\
\hline 24 & Mangifera odorata $* * *$ & 0 & 0 & 0 & $1 ., 61$ & 1,61 \\
\hline 25 & Gnetum gnemon** & 0 & 0 & 6.45 & 3,23 & 9,68 \\
\hline 26 & Artocarpus heterophyllus $* * *$ & 0 & 25,81 & 6.45 & 0 & 32,26 \\
\hline 27 & Myristica fragrans $* *$ & 0 & 64,52 & 0 & 0 & 64,52 \\
\hline 28 & Parkia speciosa** & 0 & 0 & 3.23 & 5,65 & 8,88 \\
\hline 29 & Musa paradisiaca $* * * *$ & 241,94 & 167,74 & 38.71 & 0 & 448,39 \\
\hline 30 & Alstonia scholaris* & 0 & 0 & 0 & 0,81 & 0,81 \\
\hline 31 & Ceiba pentandra** & 0 & 0 & 0 & 3,23 & 3,23 \\
\hline 32 & Eugenia palyantha** & 0 & 0 & 0 & 0,81 & 0,81 \\
\hline 33 & Dalbergia latifolia* & 0 & 0 & 3.23 & 14,52 & 17,75 \\
\hline 34 & Artocarpus communis** & 0 & 0 & 0 & 1,61 & 1,61 \\
\hline 35 & Toona sureni ${ }^{*}$ & 0 & 0 & 16.13 & 12,90 & 29,03 \\
\hline 36 & Gmelina arborea* & 80,65 & 0 & 0 & 0 & 80,65 \\
\hline
\end{tabular}

Keterangan: * = golongan kayu rimba, $* *=$ golongan MPTs rimba, $* * *=$ golongan MPTs pertanian, $* * * *=$ golongan pertanian tahunan

Berdasarkan Tabel 2 di atas fase semai golongan jenis tanaman MPTS rimba hanya ditemukan satu spesies tumbuhan yaitu durian. Untuk fase pohon intensitas ditemukannya lebih sering bahkan beberapa jenis hanya ditemukan fase pohon saja. Jika digambarkan ke dalam kurva, maka data tersebut akan berbentuk menyerupai huruf " $J$ ", hal ini menunjukkan proses regenerasi yang berjalan kurang baik. Penelitian yang dilakukan oleh Hidayat (2015) adalah bahwa di Hutan Lindung Tanjung Tiga Muara Enim Sumatera Selatan, berdasarkan kelas diameter batang, struktur tegakan di kawasan hutan ini membentuk kurva huruf L atau J terbalik, yang merupakan suatu bentuk umum yang terjadi di hutan hujan tropis. Menurut Mirmanto (2014) grafik kerapatan tanaman berdasarkan fase pertumbuhan berbentuk kurva $\mathbf{J}$ terbalik yang mana pada kurva ini menerangkan bahwa, semakin kecil fase pertumbuhan maka jumlah individunya akan semakin besar.

Upaya yang dilakukan oleh masyarakat untuk meningkatkan prodiktifitas lahan, salah satunya adalah dengan menanam tanaman bergenetik unggul yang memiliki kelebihan seperti pertumbuhan yang cepat ataupun dari segi kualitas buahnya. Tanaman MPTs merupakan salah satu komoditi utama setelah tanaman perkebunan, sedikitnya jumlah anakan tanaman yang ditemukan diduga karena masyarakat tidak menginginkan anakan tanaman yang tumbuhan secara liar. Masyarakat lebih menginginkan tanaman bergenetik unggul untuk meningkatkan produktifitas lahan menyebabkan tanaman yang tumbuh secara alami menjadi tereliminir.

Golongan tanaman MPTs pertanian yang ditemukan adalah jenis yang mudah dibudidayakan. Dalam sistem budidaya tanaman dikenal ada beberapa macam sistem perbanyakan. Perbanyakan bibit dapat diperoleh dengan cara generatif, vegetatif, dan gabungan dari keduanya. Perbanyakan tanaman secara generatif merupakan perbanyakan tanaman yang dilakukan dengan menggunakan organ generatif seperti biji atau buah. Sedangkan perbanyakan tanaman secara vegetatif dilakukan dengan menggunakan organ vegetatif seperti batang, cabang, ranting, dan akar.

Perbanyakan tanaman secara gabungan dilakukan dengan organ vegetatif dan generatif (Indriyanto, 2008). Kegiatan perbanyakan tanaman yang dapat dilakukan dengn berbagai cara, 
yaitu stek, cangkok, okulasi, sambung (grafting), dan juga perbanyakan modern seperti kultur jaringan. Namun pada kenyataannya jenis tanaman MPTs pertanian kurang dilakukannya kegiatan pembudidayaan. Hal ini dimungkinkan karena masyarakat kurang tertarik dengan jenis tanaman tersebut. Tanaman MPTs pertanian yang ditemukan masih merupakan permudaan dan jumlahnya juga masih sangat sedikit.

Berdasarkan golongan tanaman pertanian tahunan yang ditemukan semuanya merupakan komoditi utama yang dikembangkan oleh masyarakat Hutan Kemasyarakatan register 30 Gunung Tanggamus. Dari Tabel 2 juga terlihat regenerasi berjalan dengan baik, setiap jenis yang ditemukan memiliki permudaan. Pada jenis kopi robusta kerapatannya cukup besar, kerapatan yang besar menunjukkan kuantitas suatu jenis tanaman sangat banyak dalam suatu areal garapan.

Dari segi konservasi tanah jenis tanaman kopi kurang baik karena tidak dapat menahan erosi. Meylina dkk. (2015) melaporkan, besarnya tingkat erosi pada sistem tumpang sari kopi di Desa Pace Kecamatan Silo Kabupaten Jember menggunakan metode MUSLE (Modified Universal Soil Loss Equation) pada semua zona penelitian menjadi prioritas utama untuk dilakukan konservasi, karena nilai erosi pada semua zona sudah melewati batas erosi yang dapat ditolerir yaitu sebesar 12,5 ton/ha/tahun.

Adapun rata-rata jarak tanaman dapat dilihat pada Gambar 2 di bawah ini.

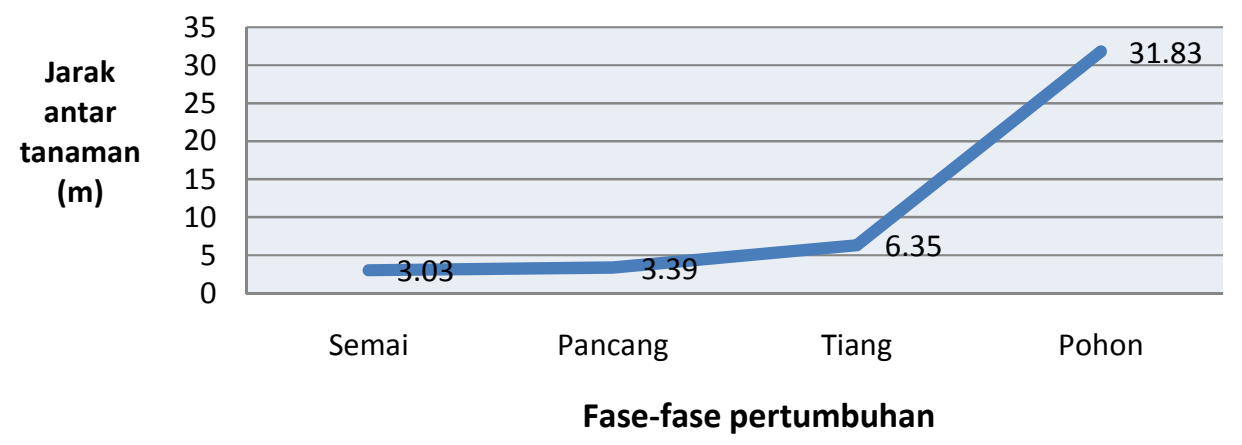

Gambar 2. Rata-rata jarak antartanaman pada setiap fase pertumbuhan

Pada Gambar 2, jarak tanaman fase pohon terlihat sangat jauh sehingga membentuk celah yang menyebabkan cahaya matahari dapat masuk dan mengenai lantai dasar hutan. Terbukti terbukanya tajuk yang lebar akan membuat tanaman yang lebih rendah mendapatkan sinar matahari yang cukup. Pada Tabel 2, kerapatan terbesar adalah golongan tanaman pertanian tahunan, golongan tanaman ini membutuhkan perlakuan khusus diantaranya mengatur intensitas cahaya matahari (Rukmana, 2014).

Pada hutan alam tegakan yang terlalu rapat menyebabkan pertumbuhan pohonpohonnya menjadi lambat karena terjadi persaingan yang keras antar pohon terhadap faktor tempat tumbuh, misalnya sinar matahari, air, dan zat hara mineral. Sebaliknya tegakan yang terlalu jarang maupun rawang (terbuka) akan menghasilkan pohon dengan tajuk lebar dan bercabang banyak dengan batang yang pendek. Kerapatan populasi dipengaruhi oleh banyak faktor lingkungan. Selain akibat pengaruh faktor lingkungan, ternyata perubahan densitas populasi dipengaruhi oleh adanya kelahiran, kematian (Indriyanto, 2006). Begitu pula yang terjadi pada areal Hutan Kemasyarakatan Kelompok Tani Rukun Makmur I Register 30 Gunung Tanggamus pertumbuhan tanaman serta kerapatan tanaman diatur sesuai kebutuhan, terutamana untuk golongan pertanian tahunan yang menjadi komoditi utama untuk meningkatkan produktifitas. 
Namun dari segi konservasi tanah vegetasi yang terbuka akan menyebabkan mudahnya permukaan tanah terkikis oleh air hujan yang jatuh ke permukaan tanah secara langsung. Menurut Arsyad (2006) air hujan yang jatuh ke suatu daerah bervegetasi akan terbagi kedalam dua bagian, yaitu bagian yang jatuh mengenai dan ditahan tajuk dan batang vegetasi disebut intersepsi, sebagian lagi langsung jatuh ke permukaan tanah disebut lolosan tajuk atau troughfall. Air yang jatuh ke tanah biasanya akan tertahan oleh serasah alami dari vegetasi yang tebentuk di hutan. Maka dari itu perlu dilakukannya penambahan tutupan tajuk pohon serta mengurangi pengolahan lahan berupa pembersihan serasah tanaman.

Tabel 3. Perbandingan jarak tanaman habitus pohon berdasarkan fase pertumbuhan

\begin{tabular}{clccc}
\hline No & Fase pertumbuhan & $\begin{array}{c}\text { total kerapatan } \\
\text { (Individu/Ha) }\end{array}$ & $\begin{array}{c}\text { rata-rata kerapatan } \\
\text { (Individu/Ha) }\end{array}$ & $\begin{array}{c}\text { rata-rata jarak } \\
\text { tanaman (m) }\end{array}$ \\
\hline 1 & Semai & 645,17 & 161,29 & 7,9 \\
\hline 2 & Pancang & 103,23 & 34,41 & 17,15 \\
\hline 3 & Tiang & 59,09 & 5,809 & 41,52 \\
\hline 4 & Pohon & 100,84 & 4,58 & 46,72 \\
\hline
\end{tabular}

Pada Tabel 3 Rata-rata jarak tanaman habitus pohon sangat besar, seharusnya jarak tanam maksimal 5m x 5m. Hal ini didasari oleh Permenhut P.87/Menhut-II/2014 Pedoman Penanaman Bagi Pemegang Izin Pinjam Pakai Kawasan Hutan Dalam Rangka Rehabilitasi Daerah Aliran Sungai yang menyatakan, untuk penanaman ruang terbuka hijau dan lahan dibebani hak milik yang berfungsi lindung, jumlah tanaman akhir, baik tanaman asal maupun tanaman baru, paling sedikit 400 (empat ratus) batang/hektar. Sesuai dengan peraturan tersebut tumbuhan bertajuk rendah tidak boleh melebihi dari jumlah tajuk tinggi, namun berdasarkan data yang diperoleh rata-rata kerapatan fase pohon hanya 4,5 individu/ha. Jumlah tersebut sangat kurang memenuhi syarat fungsi hutan lindung sebagai penahan erosi dan tata air yang seharusnya berjumlah minimum 400 batang/ha. Dengan demikian, Kelompok Tani Rukun Makmur I Register 30 Gunung Tanggamus belum dapat memenuhi kewajiban sebagai pemegang izin pakai kawasan hutan.

Tabel 4. Perbandingan kerapatan tanaman berdasarkan golongan jenis tanaman

\begin{tabular}{rlrr}
\hline No & \multicolumn{1}{c}{ Kelompok Jenis } & \multicolumn{1}{c}{$\begin{array}{c}\text { Kerapatan } \\
\text { (individu/ha) }\end{array}$} & Persentase Kerapatan (\%) \\
\hline 1 & Kayu rimba & 412,44 & 18,65 \\
\hline 2 & MPTS & 69,68 & 3,15 \\
\hline 3 & Pertanian tahunan & 1729,03 & 78,20 \\
\hline 4 & Pertanian semusim & 0 & 0,00 \\
\hline Total & $2.211,15$ & 100,00 \\
\hline rata-rata jarak antar tanaman $(\mathrm{m})$ & & 2,13 \\
\hline
\end{tabular}

Berdasarkan Tabel 4 persentase kerapatan jenis tanaman pertanian tahunan lebih besar dibanding jenis tanaman kayu-kayuan dan MPTs. Hal ini disebabkan tanaman pertanian merupakan sumber penghasilan utama masyarakat pemegang IUPHKm, sehingga hutan lindung yang tadinya didominasi tanaman kekayuan dirubah menjadi lahan pertanian. Lahan hutan lindung yang menerapkan skema $\mathrm{HKm}$ sesuai dengan peraturan yang ada boleh melakukan pola tanam agroforestry, dengan ketentuan tanaman tajuk tinggi harus lebih mendominasi agar fungsi utama hutan lindung tetap terjaga.

Berdasarkan Permenhut P. 70/Menhut-II/2008 tentang pedoman teknis rehabilitasi hutan dan lahan, untuk memenuhi kepentingan ekologi, ekonomi dan sosial, maka dalam kegiatan reboisasi dapat diadakan pencampuran tanaman antara jenis kayu-kayuan dan jenis 
MPTs dengan komposisi minimum 60\% kayu-kayuan, maksimum 40\% MPTs (penghasil kayu, getah, buah, kulit). Perbandingan kelompok tanaman kayu rimba dengan MPTs di lokasi penelitian yaitu $85,55 \%$ berbanding $14,45 \%$. Hal ini menunjukkan secara komposisi, bahwa Kelompok Tani Rukun Makmur 1 telah memenuhi kewajiban sebagai pemegang IUPHKm. Selain tanaman kekayuan dan MPTs ditemukan juga kelompok tanaman pertanian tahunan diantaranya tanaman kopi memiliki kerapatan sebesar 4.416,13 individu/ha, tanaman lada memiliki kerapatan sebesar 322,58 individu/ha, dan pisang memiliki kerapatan sebesar 448,39 individu/ha.

\section{Stratifikasi Tajuk}

Stratifikasi tajuk diklasifikasikan berdasarkan stratum-stratum yang dibagi menjadi 5 stratum berdasarkan tinggi pohon dari setiap spesies di areal HKm Rukun Makmur 1 Register 30 Gunung Tanggamus. Jumlah spesies pada setiap stratum selengkapnya disajikan pada Gambar 3 berikut ini.

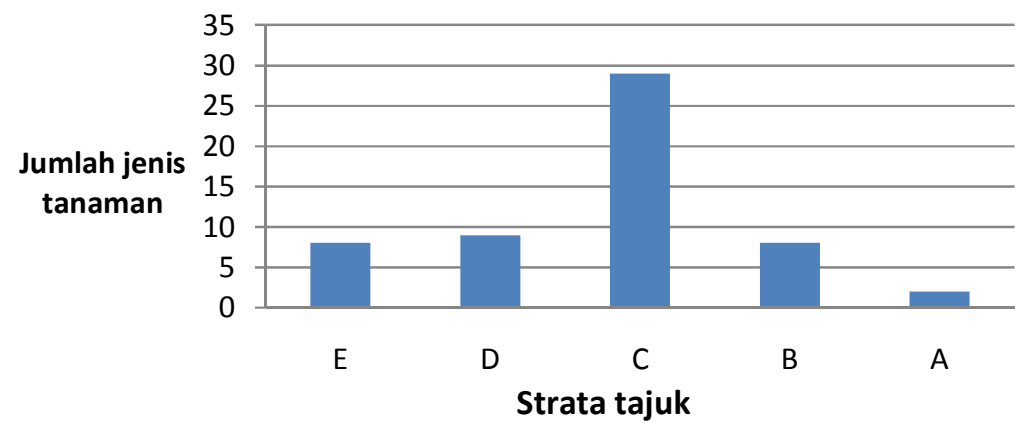

Gambar 3. Jumlah jenis tanaman pada setiap stratum di areal HKm Rukun Makmur 1 Register 30 Gunung Tanggamus.

Pada Gambar 3 membentuk kurva lonceng dimana tratum $\mathrm{C}$ memiliki jenis terbanyak dengan jumlah 29 jenis. Keadaan ini merupakan fenomena yang normal untuk kondisi hutan alam dimana stratum $\mathrm{C}$ sebagai permudaan yang nantinya akan menggantikan kelas umur diatasnya. Namun bila keadaan menggambarkan stratum A memiliki jenis yang lebih tinggi kemudian stratum dibawahnya semakin sedikit, dimungkinkan adanya penghilangan jenis akibat proses pengelolaan lahan.

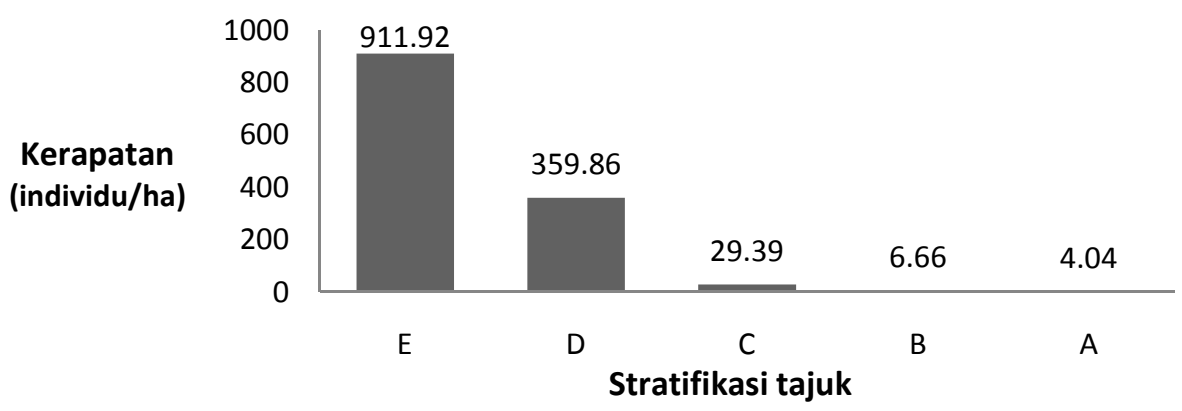

Gambar 4. Kerapatan pada setiap stratum di areal HKm Rukun Makmur 1 Register 30 Gunung Tanggamus. 
Seperti terlihat pada Gambar 4 bahwa tegakan tidak seumur memiliki distribusi menurut kelas kerapatan berbentuk J terbalik. Jumlah kerapatan terbesar berada dalam kelas diameter terkecil, lalu jumlahnya menurun kurang lebih sebanding dengan bertambahnya ukuran diameter, sehingga pepohonan yang ukuran diameternya paling besar memiliki jumlah sedikit. Struktur tegakan seperti di atas menggambarkan bahwa di areal HKm Rukun Makmur 1 Register 30 Gunung Tanggamus proses regenerasi tegakan berjalan dengan baik karena terdapat anakan pohon dengan kondisi kerapatan fase semai $>$ fase pancang $>$ fase tiang $>$ fase pohon (Indriyanto, 2008). Menurut Suwardi (2013) ketersediaan tegakan pada hutan yang bertipe normal akan membentuk kurva J terbalik sangat tinggi, sehingga dapat menjamin keberlangsungan tegakan di masa mendatang. Menurut Widiyanti dkk. (2014) struktur horizontal vegetasi hutan yang membentuk kurva $\mathrm{J}$ terbalik akan menunjukan proses suksesi sekunder yang berjalan baik sejalan dengan pertambahan waktu.

\section{SIMPULAN DAN SARAN}

\section{Simpulan}

Berdasarkanpenelitian yang telah dilakukan dapat ditarik kesimpulan sebagai berikut:

1. Jenis tanaman yang ditemukan pada areal Hutan Kemasyarakatan Rukun Makmur I di Register 30 Gunung Tanggamus berjumlah 36 jenis terdiri dari golongan kayu rimba 14 jenis, MPTs rimba 10 jenis, MPTs pertanian 9 jenis, pertanian tahunan 3 jenis, dan pertanian semusim 0 jenis.

2. Kerapatan tertinggi ada pada golongan tanaman pertanian tahunan yaitu fase semai 699 individu/ha, fase pancang 804 individu/ha, fase tiang 226 individu/ha. Sedangkan untuk rata-rata jarak tanaman secara keseluruhan golongan tanaman berdasarkan fase pertumbuhanya itu fase semai 3,03 meter, fase pancang 3,39 meter, fase tiang 6,35 meter, dan fase pohon 31,83 meter.

3. Vegetasi areal hutan kemasyarakatan Rukun Makmur I Register 30 Gunung Tanggamus memiliki stratifikasi tajuk lengkap yang terdiri dari lima strata yaitu strata A, B, C, D, dan E.

\section{Saran}

Adapun saran yang dapat diberikan pada penelitian ini adalah sebagai berikut.

1. Jenis tumbuhannya tergolong sangat sedikit sehingga diperlukan pengayaan jenis tumbuhan dengan jenis-jenis yang sesuai tempat tumbuhnya dan disukai oleh syarakat, jenis tersebut bisa berasal dari daerah setempat atau dari luar wilayah setempat sehingga kawasan ini juga mampu menunjang pertanian dengan cara menyediakan sumber genetika. Hutan lindung berfungsi sebagai penjaga tata air dan keburan tanah terutama di bagian bawah sehingga apabila didalam hutan tersebut terdapat berbagai macam sumber genetika maka ada kesempatan untuk mendapatkan sumber tanaman bergenetik unggul. Keunggulan lainnya jika sumber genetika berneka ragam dapat menyediakan musuh alami bibit penyakit, sehingga jika terdapat wabah penyakit tidak terlalu besar akibatnya terhadap tanaman.

2. Kerapatan fase pohon sangat rendah sehingga perlu dilakukan upaya penambahan jumlah pohon agar dapat menjaga fungsi pokok dari hutan lindung. 


\section{DAFTAR PUSTAKA}

Arsyad, S. 2006. KOnservasi Tanah dan Air. Buku. IPB PRESS. Bogor. 396 p.

Balai Rehabilitasi Lahan dan Konservasi Tanah Way Sekampung Seputih Provinsi Lampung. 2000. Meningkatkan Manfaat Hutan Melalui Hutan Kemasyarakatan. Balai Rehabilitasi Lahan dan Konservasi Tanah Way Sekampung Seputih Provinsi Lampung. Bandar Lampung. 6 p.

Hidayat, S. 2015. Komposisi dan Struktur Tegakan Penghasil Kayu Bahan Bangunan di Hutan Lindung Tanjung Tiga Muara Enim Sumatera Selatan. Jurnal Manusia dan Lingkungan. Pusat Konservasi Tumbuhan Kebun Raya Bogor. Bogor. 22(2) : 194-200.

Indriyanto. 2006. Ekologi Hutan. Buku. Penerbit Bumi Aksara. Jakarta. 210 p. . 2008. Pengantar Budi Daya Hutan. Buku. Penerbit Bumi Aksara. Jakarta. 234 p.

Meylina, E., Wahyuningsih, S., Pudjojono, M. 2015. Estimasi Tingkat Erosi Pada Sistem Tumpang Sari Kopi - Tanaman Semusim Menurut Metode MUSLE (Modified Universal Soil Loss Equation) di Desa Pace Kecamatan Silo Kabupaten Jember. Jurnal Teknologi Pertanian. Universitas Jember. Jember. V 1, No 1, P. 1--6.

Mirmanto, E. 2014. Komposisi Floristik dan Struktur Hutan di Pulau Natuna Besar Kepulauan Natuna. Jurnal Biologi Indonesia. Pusat Penelitian Biologi LIPI. Bogor. $10(2): 201--211$.

Pemerintah Desa Datarajan. 2014. Monografi Desa Datarajan. Tidak Diterbitkan. 32 p.

Permenhut P. 88/Menhut-II/2014 tentang Hutan Kemasyarakatan. 21 p.

Permenhut P. 87/Menhut-II/2014 tentang Pedoman Penanaman Bagi Pemegang Izin Pinjam Pakai Kawasan Hutan Dalam Rangka Rehabilitasi Daerah Aliran Sungai. 33 p.

Rukmana, H. R. 2014. Untung Selangit dari Agribisnis Kopi. Buku. LILY PUBLISHER. Yogyakarta. $344 \mathrm{p}$.

Suwardi, A. B. 2013. Komposisi Jenis dan Cadangan Karbon di Hutan Tropis Dataran Rendah Ulu Gandut Sumatera Barat. Jurnal Biologi. Universitas Andalas Padang. Padang Sumatera Barat. 12(2) : 168--176.

Undang Undang Republik Indonesia Nomor 41 Tahun 1999 Tentang Kehutanan. 62 p.

Undang Undang No. 6 Tahun 2007 tentang Tata Hutan dan Penyusunan Rencana Pengelolaan Hutan, serta Pemanfaatan Hutan. 106 p.

Unit Pelaksana Terpadu KPH Batu Tegi. 2007. Profil Gabungan Kelompok Tani Koperasi Patria Panca Marga. Unit Pelaksana Terpadu KPH Batu Tegi. 86 p.

Widiyanti, P., dan C. Kusmana. 2014. Komposisi Jenis dan Struktur Vegetasi Pada Kawasan Karst Gunung Cibodas Kecamatan Ciampea Kabupaten Bogor. Jurnal Silvikultur Tropika. Institut Pertanian Bogor. Bogor. 5(2) : 69--79. 
Widiyanto. 2007. Study Kondisi Vegetasi Hutan Di Areal Hutan Kemasyarakatan Kawasan Register 45B Bukit Rigis Pekon Tribudi Syukur Lampung Barat. Skripsi. Universitas Lampung. Lampung. 103 p.

Yusuf, R., Purwaningsih, dan Gusman,. 2005. Koposisi dan Struktur Vegetasi Hutan Alam Rimbo Panti Sumatra Barat. Jurnal Biodiversitas. FMIPA Universitas Andalas. Padang. Vol. 6. No. 4. P. 266 -- 271 